\title{
Avant-propos. La muséologie en contextes indigènes
}

\section{Bruno Brulon Soares}

Traducteur : Marion Bertin

\section{(2) OpenEdition Journals}

Édition électronique

URL : https://journals.openedition.org/iss/2982

DOI : $10.4000 /$ iss. 2982

ISSN : 2306-4161

Éditeur

ICOM - International Council of Museums

\section{Édition imprimée}

Date de publication : 18 décembre 2021

Pagination : 11-12

ISBN : 978-92-9012-446-7

ISSN : 2309-1290

Référence électronique

Bruno Brulon Soares, "Avant-propos. La muséologie en contextes indigènes », ICOFOM Study Series [En ligne], 49-1 | 2021, mis en ligne le 18 décembre 2021, consulté le 08 janvier 2022. URL : http:// journals.openedition.org/iss/2982; DOI : https://doi.org/10.4000/iss.2982 


\section{Avant-propos}

\section{La muséologie en contextes indigènes}

Le nouveau numéro des ICOFOM Study Series réunit les présentations du symposium annuel d'ICOFOM en 2020 sur le thème "La muséologie en contextes indigènes », organisé en format virtuel par le Southern New Hampshire University (États-Unis d'Amérique). Ce symposium a été élaboré par ICOFOM avec le soutien d'ICOM-US, the Association of African American Museums et Southern New Hampshire University, dans le but d'inviter des personnes entreprenant des pratiques indigènes en tant que sources d'inspiration pour une conception critique de la théorie muséologique en prenant pour point de départ leurs propres perspectives et compréhension indigènes du patrimoine culturel et des musées.

Bien que situé aux États-Unis d'Amérique, ce symposium en ligne a permis de réunir des membres d'ICOFOM issus de différents contextes mondiaux et d'impliquer des professionnel.le.s des musées autour d'une approche décoloniale de la théorie muséologique. Des participant.e.s de 48 pays différents se sont inscrit.e.s. L'hypothèse que les perspectives « indigènes » sur le musée pourrait aider à ouvrir la muséologie à d'autres épistémologies et construire des interprétations situées du patrimoine culturel étaient au centre des débats poursuivis pendant ce riche évènement. Décoloniser la muséologie est un exercice actif et continu auquel ICOFOM se confronte par le biais du projet « Musées, actions communautaires et décolonisation ", dont les résultats ont inspiré une série de wébinaires et la conception de notre symposium annuel organisé pendant la pandémie de Covid-19. Ce moment critique pour nos sociétés et pour les musées à l'échelle mondiale a rendu explicite certains problèmes structurels de notre époque et a soulevé des questions essentielles sur la participation de différents groupes et minorités dans le secteur culturel.

Nous souhaitons que les articles sélectionnés pour ce numéro pourront aider à apporter une lumière sur les défis actuels de la muséologie, en soulignant certains des principaux problèmes que la théorie telle que nous la connaissons n'était pas capable de dépasser par le passé. Ainsi, les articles traitent de sujets variés, des restitutions au relations des musées avec le marché de l'art et le droit des populations autochtones de s'exprimer et de devenir elles-mêmes autrices de leurs propres représentations dans les musées. En ce sens, ce numéro est la première partie du débat «Décoloniser la muséologie », devenu le thème central de ce journal en 2021 et qui sera exploré plus avant dans notre prochain volume, prévu un peu plus tard cette année. 
Je remercie les membres de notre Comité de rédaction et les pairs pour les relectures, qui ont travaillé dur dans les mois derniers pour qu'ICOFOM Study Series puisse rester une publication active, même dans une période compliquée. Ce numéro est le résultat d’un travail éditorial direct mené par plusieurs professionnel.le.s, parmi lesquel.le.s les éditeur.rice.s invité.e.s, Yun Shun Susie Chung et Robert Denning de Southern New Hampshire University, qui furent nos partenaires tout au long de ce projet, les secrétaires éditoriales Anna Leshchenko, Marion Bertin, Lynn Maranda, Elizabeth Weiser et Scarlet Galindo Monteagudo, ainsi que les relectrices Katherine Sleight, Marie-Alix Molinié-Andlauer et Sophia Tidwell, qui ont tous et toutes accompli un travail incroyable. Un grand merci à tou.te-s les auteur.rice.s des articles publiés ici pour avoir partagé leurs expériences enrichissantes et pour avoir ouvert la voie à de nouvelles perspectives sur les muséologies indigènes et localisées.

Bruno Brulon Soares

Rio de Janeiro, Brazil.

Traduction par Marion Bertin 